\title{
Current Practices of Organ Donation and Transplantation Among Different French-Speaking Countries and Regions
}

\author{
J.P. Squifflet, B. Barrou, and G. Rifle
}

\begin{abstract}
The aim of the "Transplantation Sans Frontières" (TSF) questionnaire, which was sent to French-speaking centers in 6 different countries and regions, was to establish the current status of organ donation and transplantation in their environments. It was also to examine ways to collaborate and exchange scientific information, teaching, and training in the field of organ transplantation. The French Society of Transplantation and the Agency of Biomedicine already offer specific programs to expand local activities, and the World Health Organization (WHO) regulates them. Therefore, TSF could be a coordinating platform in the near future.
\end{abstract}

$\mathbf{T}$ o develop scientific collaborations and exchange knowledge in the field of organ donation and transplantation among the "Société Francophone de Transplantation" (SFT), the French Agency of Biomedecine (ABM), with the help of the World Health Organization (WHO), and transplantation centers in French-Speaking regions and countries, the SFT created a common platform called "Transplantation Sans Frontières" (TSF).

During the tenth SFT congress in Geneva, the first TSF symposium was organized to update the current practices in organ donation and transplantation among various Frenchspeaking countries or regions. It also sought to increase and coordinate existing fruitful collaborations and scientific exchanges. To prepare for the TSF symposium, a questionnaire was sent to members in various French-speaking countries and regions. The TSF questionnaire assessed current practices, the possible role of SFT or ABM, and the impact of the WHO regulation.

\section{METHODS}

The TSF questionnaire was divided into 4 parts. The first part was designed to establish the current status of organ donation and transplantation by asking for demographic data, including the number of transplantation centers, the date of the first and the total number of renal transplantations, the proportion of live versus cadaveric donors, the date of the first cadaveric procurement, the date of the first donor after cardiac death (DCD) procurement, the proportion of $\mathrm{DCD} /$ donor in brain death (DBD), and the number of extra renal transplantations. The second part concerned the scientific environment by asking about the existence of local transplantation societies, their number of meetings, their ways of teaching and training for transplant physicians and surgeons, their collaborations with other transplantation societies and/or centers, their funding, and their expectations of the SFT. The third part was devoted to the WHO convention by asking for evaluation of transplantation tourism and its causes, the attractive countries and the motivation, the collaboration between states or centers, the existence of live donor registries, compensation for live donation, the possible application of the Iranion system, and the organization of follow-up of patients transplanted abroad. The last part concerned the local support from health authorities and the role that the $\mathrm{ABM}$ and/or the Eurotransplant organization could add to their practices. The TSF questionnaire was available on the SFT website from October 1, 2010. It was also electronically sent to 2-5 SFT members in each French-speaking country and/or region; to avoid overlapping information, we cross-checked the reported data.

\section{RESULTS}

French-speaking transplantation centers from 6 different countries answered the TSF questionnaire: Macedonia, Moldavia, Algeria, Vietnam, Canada (Québec), and Brazil. They could be divided into 3 subgroups of 2 countries according to the current status of organ donation and transplantation (Table 1). The first, Macedonia and Moldavia, started renal transplantation programs in the late

From the Department of Abdominal Surgery and Transplantation, (J.P.S.) University of Liège, Liège, Belgium; Department of Urology and Transplantation, (B.B.) Hôpital de la Pitié, Paris, France; and Department of Nephrology and Transplantation, (G.R.) University Hospital, Dijon, France.

Address reprint requests to Professor Jean-Paul Squifflet, MD, $\mathrm{PhD}$, Department of Abdominal Surgery and Transplantation, CHU Sart Tilman, B 35, 4000, Liège, Belgium. E-mail: jeanpaul.squifflet@chir-transplantation.be 
Table 1. Current Status of Organ Donation and Transplantation in French-Speaking Centers from 6 Different Countries

\begin{tabular}{lcccccc}
\hline & Macedonia & Moldavia & Algeria & Vietnam & Canada (Québec) & Brazil \\
\hline Date of first renal transplant & $07 / 07 / 1977$ & $24 / 09 / 1982$ & $14 / 06 / 1986$ & 1992 & 1958 & 1960 \\
Total number & 350 & 242 & 683 & $600-700$ & 6,371 & $>20,000$ \\
Number per year & $\sim 25$ & $\sim 20$ & $\sim 100$ & $\sim 100$ & $>210$ & $\sim 3,500$ \\
Proportion live vs cadaver donors & $90 \%$ & - & $100 \%$ & $100 \%$ & $>20 \%$ & $45-55 \%$ \\
Date of first DBD & $11 / 1987$ & - & $12 / 2002+03 / 2010$ & $05 / 2010$ & 1963 & 1970 \\
Date of first DCD & - & $24 / 09 / 1982$ & & - & - & 2007 \\
\hline
\end{tabular}

Abbreviations: DBD, donation after brain death; DCD, donation after cardiac death.

1970s or early 1980 s with $250-350$ total renal transplantations. Despite recognition of brain death (DBD) in Macedonia, live donation provides the major source of kidneys. In contrast, in Moldavia, renal transplantation started with DCD. In the second subgroup are Algeria and Vietnam, with only living-donor transplantations; 2 DBDs reported in Algeria were: in Oran in December 2002 and in Blida in March 2010. ${ }^{1}$ Only 1 DBD has been reported in Vietnam, ${ }^{2}$ but in contrast to the 2 DBDs in Algeria, the DBD in vietnam was a multiple-organ donor who gave life to 4 recipients: 1 heart, 1 liver, and 2 kidneys). The last subgroup, Canada and Brazil, began kidney transplantations in 1958 and 1960, respectively. DBD is the major source, but living donation is also promoted; DCD has not yet been implemented in Brazil.

All 6 countries, except for Macedonia and Vietnam, have a scientific society for organ transplantation. Most transplant physicians and surgeons were trained in the USA and/or EU countries. But local training for cadaver organ procurement is usually lacking except for Canada, where a 2-year fellowship is organized. Local funding for training is not yet adequate.

All 6 countries have declared to adhere to the Istanbul Convention, ${ }^{3}$ but only Macedonia has reported a live-donor registry to follow donors. Only in Canada are donor hospitalization and other costs are covered; Canada also has a compensation system for salary losses. ${ }^{4}$ But compensation like the Iranian system could be applied only in Algeria and Vietnam. Moreover, it would require profound modifications and adaptation to the local social security systems. There are still patients traveling in Macedonia, Moldavia, Algeria, and Vietnam for transplantation. In Canada, it is based on a general agreement that intestinal transplantation is located at only a single center. Abroad destinations include India, Pakistan, Egypt, Russia, Jordanian, Iraq, China, Emirates, and Philippines, as well as France, Italy, and Spain in specific cases. For the last 3 destinations, the general cost to the local social security varies from 2,000 to 50,000 euros. The follow-up of these recipients is performed locally, with special rules in Canada. ${ }^{4}$ Except for Canada and Brazil, transplantation agencies such as the $\mathrm{ABM}$ and/or Eurotransplant do not exist, but contacts are made or are ongoing between the ABM and Moldavian, Vietnamese, and Algerian health authorities.

\section{DISCUSSION}

French-speaking centers in 6 different countries and regions answered the TSF questionnaire, establishing the current status of organ donation and transplantation in their environment. We examined ways to collaborate and exchange scientific information, teaching, and training in the field of organ transplantation. The SFT and the ABM already offer specific programs to expand local activities as regulated by WHO. Therefore, in the future TSF could be a coordinating platform. All French-speaking centers that are exclusively performing living-donor transplantations are willing to implement and increase deceased-donor procurement activities. But despite local laws favoring or recognizing DBD, cultural backgrounds are the major hurdle to develop such organ sources. In Moldavia, where DCD was the major source for organ donation since the 1980s, the program had been stopped. But with ABM help and local input, a brand new Moldavian agency was recently created with reactivation of a DCD program as a first step.

All French-speaking centers already involved for many years in DBD are currently willing to develop DCD among all Maastricht categories. But living altruistic donation must be also expanded with ABO-incompatible programs, especially for hyperimmune candidates. Therefore, supranational collaborations are needed, as recently promoted by the European Union. ${ }^{5-7}$ It is already ongoing for intestinal transplantation in Canada. ${ }^{4}$

For the future, the SFT will continue to favor scientific exchanges, fellowships, protocols, and training within the French-speaking centers all over the world. WHO is and will be the promoter and guardian of ethics in the field of organ transplantation. The ABM and its model, as well as other transplantation organization models, must be promoted. Therefore, "Transplantation Sans Frontières" is and will be a coordinating platform, knowing the diversity of the procedures as well as, the organization and management within each of the French-speaking centers. This should improve the quality of care in Francophonia for both candidates and transplant recipients as well as help Frenchspeaking regions to address inherent ethical and scientific difficulties.

\section{ACKNOWLEDGEMENTS}

The authors thank Pr Dr N. Ivanovski, Z. Popov, and K. Cakalaroski (Skopje, Macediona); Pr Dr G. Romanciuic and A. Codreanu 
(Chisinau, Moldavia); Pr Dr M. Benabadji, T. Rayane, Atik and E. Si Ahmed (Alger and Blida, Algeria); Pr Dr Hieu Ledinh (Ho Chi Minh City, Vietnam); Pr Dr P. Daloze, I. Houde, M. Cantarovich, F. Mosiman, and J. Malaise (Montréal and Sherbrook, Québec, Canada); and Pr Dr Ribeiro de Castro (Pereira, Campos, Brazil).

\section{REFERENCES}

1. Si Ahmed E, Blida Transplantation Team: The first cadaver organ procurement in Blida. Transplant Proc 43, 2011

2. Hieu L: Landmarks in clinical solid organ transplantation in Vietnam. Transplant Proc 43, 2011

3. The Declaration of Istanbul on organ trafficking and transplant tourism. Transplantation 86:1013, 2008
4. Gill JS, Goldberg A, Ramesh Prasad GV, et al: Policy statement of Canadian Society of Transplantation and Canadian Society of Nephrology on Organ Trafficking and Transplant Tourism. Transplantation 90:817, 2010

5. Communication from the Commission, Action Plan on Organ Donation and Transplantation (2009-2015): Strengthened Cooperation between Member States, COM (2008) 819 final.

6. Dir. (UE) no. 2010/45 UE of the European Parliament and of the Council of 7 July 2010 on standards of quality and safety of human organs intended for transplantation, O.J.E.U., L. 207, 6 August 2010, pp 14-29

7. Squifflet AC: L'action de l'Union européenne (UE) en matière de prélèvement et de transplantation d'organes: commentaires à propos du plan d'action 2009-2015 et de la directive du 7 juillet 2010. Rev Dr Santé/T Geza 382:5, 2011 